\title{
RESEARCH
}

\section{Readiness, Reception, and Performance of Students in a Communications Course Delivered Amid the Pandemic}

\author{
Alamdar Hussain, PhD, ${ }^{\mathrm{a}}$ Jasen Chau, PharmD, ${ }^{\mathrm{a}}$ Heejung Bang, PhD,${ }^{\mathrm{b}}$ Lee Meyer, PharmD, ${ }^{\mathrm{a}}$ Mohammed Islam, \\ $\mathrm{PhD}^{\mathrm{a}}$
}

\author{
${ }^{a}$ American University of Health Sciences, School of Pharmacy, Signal Hill, California \\ ${ }^{\mathrm{b}}$ University of California, Division of Biostatistics, Davis, California
}

Corresponding Author: Alamdar Hussain, American University of Health Sciences, School of Pharmacy, 1600 E Hill St., Signal Hill, CA 90755. Tel: 562-988-2278. Email: ahussain@auhs.edu

Submitted February 26, 2021; accepted May 2021; ePublished May 2021

Objective. To examine pharmacy student readiness, reception, and performance in a communications course amid the COVID-19 pandemic.

Methods. First-year pharmacy students (2020 cohort) enrolled in a professional communications course completed a preand post-course questionnaire indicating their readiness and changes in reception toward online learning during the pandemic. Student learning performance (midterm and final examination grades) at the end of the course was compared with that of a class which took the same course face-to-face on campus the previous year (2019 cohort).

Results. Student preference for face-to-face instruction decreased (difference in means $=-1.59 ; p<.05$ ), while their comfort level for online learning increased (difference in means $=+0.38, p<.05$ ) by the end of the course. No appreciable changes in rapport development with the instructor were perceived by the end of the study compared to the beginning. Student learning performance for the online cohort did not differ significantly $(p>.05)$ compared to that of the 2019 cohort.

Conclusion. The study demonstrates that students were partly prepared for online learning with the remainder of their maturation to it occurring while the quarter progressed. Remote online learning did not seem to impact student learning (grades) in this communications course during the COVID-19 crisis. Looking past the pandemic, educators and leadership at pharmacy schools and colleges may reassuringly continue to sustain online instruction, where deemed necessary, in their didactic curricula.

Keywords: remote learning, online instruction, communications, pandemic crisis, student readiness

\section{INTRODUCTION}

Remote online learning or e-Learning refers to an instructional process in a classroom environment where students are physically distant from the instructor. ${ }^{1}$ As early as 1993, the Alfred P. Sloan Foundation initiated programs on networkenabled, self-paced learning for students without time and space constraints. ${ }^{2}$ Currently, e-Learning comprises of two principal categories: Distance learning and Computer-assisted learning. ${ }^{3}$ Despite some differences in pedagogical methodologies, terms such as web-based, virtual, online, distributed, and internet-based learning, among others, have been used synonymously to refer to e-Learning. For the clarity of this communication, the authors use the term 'online learning' to indicate 'synchronous online learning' where the students and instructor are remotely interconnected by computer technology.

Several advantages and barriers to e-Learning are cited in the literature. The advantages include easy accessibility with flexibility, ${ }^{4}$ increased class participation, ${ }^{5}$ and learning outcomes as good as those achieved in traditional instructional settings. ${ }^{6,7}$ Some of the limitations noted for e-Learning include technical difficulties, ${ }^{6}$ reduced interaction and discussion with peers, ${ }^{8}$ inability to virtualize every aspect of learning (eg, hands-on laboratory experience),${ }^{9}$ lack of professional growth due to absence of in-person role models, ${ }^{8}$ sub-optimal communication skills development, ${ }^{10}$ and increased risk of isolation and anxiety. ${ }^{11}$ Over the last decade, there has been a gradual shift to e-Learning in pharmacy education with both required and elective courses being delivered virtually. Some of these courses were entirely virtual while others were a hybrid of virtual and face-to-face instruction. ${ }^{12-15}$

Effective communication plays a vital role in the professional practice of a pharmacist. A late 1990s report from the World Health Organization detailed seven crucial roles of a pharmacist in the healthcare system, one of which is 'Communicator' ${ }^{16}$ Pharmacists are expected to possess good communication skills, including empathy and critical thinking, with the ultimate objective of improving health outcomes and overall patient satisfaction. A review by Wallman and 
colleagues summarized various skills and topics taught to students. ${ }^{17}$ Among these, oral communication skills were found to be the most taught followed by written communication skills. Both simulated and standardized-patient interaction teaching methods are currently employed. ${ }^{17}$

The outbreak of COVID-19 brought challenges in all facets of life, including academic teaching and learning. By early summer 2020, journals in various healthcare professions began publishing papers discussing the unique challenges and opportunities faced by educators in the wake of the pandemic. The Journal devoted its June 2020 issue exclusively to addressing the problems and presenting solutions by pharmacy educators. These communications covered a gamut of exigencies, ranging from accreditation of pharmacy programs to student enrollment to sustainable pharmacy education to facilitating the well-being of students and faculty during the pandemic crisis. In particular, Lyons and colleagues provided pragmatic solutions to delivering emergency remote teaching. ${ }^{18}$ Their suggestions included providing synchronous lectures through a video conferencing platform (such as Zoom), developing quizzes as pass or fail, and utilizing breakout rooms for small group discussions and activities, among other measures. Although much has been discussed about online teaching for educators, there is very little information available from the student perspective about online learning amid the pandemic. For example, were pharmacy students ready for receiving course instruction and being evaluated entirely online during the crisis?

A pre-pandemic report by Wei and colleagues discussed the notion of readiness in online instruction. ${ }^{19}$ Student comfort with learning resources, degree of self-direction, beliefs about distance education, and a desire for interaction with peers and instructors were identified as components of readiness. Additionally, while Dray and colleagues considered access to, nature of, frequency of usage, and comfort with technology as components of readiness, ${ }^{20} \mathrm{Yu}$ and Richardson viewed factors such as social competencies with peers and instructors, among others, as prime determinants of readiness to online learning. ${ }^{21}$ In the context of the present study, these are all valid components of readiness.

It was vital for our group to investigate whether a course such as communications, which relied heavily on interpersonal development and learning, would fare well with respect to its reception, instructor interaction, and student performance when transitioned in a hurry to online learning in its entirety. The students and instructor did not meet inperson anytime during the course due to the social distancing restrictions mandated by the state and the university. Thus, the primary objective of the present study was to evaluate student readiness and monitor changes in reception for a completely online communications course delivered amid the COVID-19 pandemic. The secondary objective of the study was to compare student learning performance in the online course with that of students who took the same course on campus (ie, face-to-face) coordinated by the same instructor in the previous year.

\section{METHODS}

Professional Communications (AS736) is a required 3-credit hour course taught in the first quarter (summer quarter) of the first year of the PharmD program at the American University of Health Sciences School of Pharmacy. The course introduces students to the concepts and principles of interpersonal/ professional communication and strategies for effective communication with patients and other healthcare providers. In addition, the role of health literacy as well as cultural influence on communication of health information is taught. Communication skills covered in the course include motivational interviewing, listening, nonverbal communication, addressing patients' needs and preferences, and assertive communication. Content of the course also included active learning, watching videos, case studies, discussions, feedback, and homework. The course learning outcomes were a) Recognizing and applying concepts and principles of interpersonal growth, leadership, and professionalism for effective communication with patients and other health care providers, b) Identifying proper approaches to coaching, mentoring, teamwork, and conflict resolution, c) Applying communication strategies of culture, race, and ethnicity, d) Demonstrating altruism, integrity, trustworthiness, flexibility, and respect in all interactions, e) Empowering patients to take responsibility and control of their health, and f) Delivering patient-centered care through consultation in a manner that is legal, ethical, and compassionate.

In summer 2019, the course was organized into 15 lectures and in summer 2020, it was organized into 16 lectures. In 2019, the course was delivered face-to-face with students attending the course in a classroom on campus, and taking assessments in a traditional manner with the course coordinator proctoring them in a classroom. However, in 2020, the course was delivered entirely online using the video conferencing platform, Zoom (San Jose, CA), with no in-person interaction between students and the instructor. To maintain academic integrity of assessments administered in the online class, students' test-taking was remotely monitored by Proctorio. ${ }^{22}$ The class demographics for the two cohorts and data for technology use by the 2020 cohort are presented in Table 1.

Student learning performance in AS736 for the two cohorts was assessed by the following class activities: Pharmacist interviews, professional memo, patient education pamphlet, objective structured clinical examination (OSCE) role-play, quizzes, and midterm and final examinations. Pharmacist interview is an assignment where students conduct an in-person interview of a pharmacist on beliefs and attitudes related to the profession. Professional memo is an activity 
wherein students write a memorandum to develop professional writing skills to address a situation, topic, or concern. Patient education pamphlet is educational material created by students as a tool to communicate medical information to a layperson in easy-to-comprehend language. In OSCE role-play, students apply patient counseling skills by mutually role-playing as pharmacist and patient, and exchanging information, demonstrating effective listening skills, expressing sympathy, and ensuring patient advocacy. The quizzes, midterm, and final examination were assessed using conventional multiple-choice answer format, whereas pharmacist interviews, professional memo, patient education pamphlet, and OSCE role-play were assessed using instructor-designed grading rubrics. The overall topics taught in AS736 and assessments rendered for the two cohorts were similar except the mode of delivery (face-to-face vs. online).

Student readiness and reception to online learning for the 2020 cohort were evaluated by an anonymous pre-survey (also referred to in this paper as pre-test), and an anonymous post-survey (also referred to as post-test). The pre-test was administered in the first week of the quarter when the course began, and the post-test was administered in the last week of the quarter when the course ended. The survey was designed to gather student readiness and reception to online learning in three primary domains: Transition to online learning (6 questions), Ease of technology including taking assessments remotely (3 questions), and Instructor interaction (3 questions). The survey instrument was drafted by gathering items through a review of literature pertaining to distance and online education in the healthcare field. ${ }^{12,21,23}$ The survey instrument underwent two iterations by three faculty members (one of whom belonged to a different pharmacy school). A final optimized version of the instrument was used in the study. A Google link containing either the pre- or post-survey instrument was sent out, in respective weeks, via email to all students of the 2020 cohort. Additionally, the survey instrument's uniform resource locator (URL) was made available on the announcement page of the course management system (Canvas) so students would remember to complete it when they logged-on to Canvas. Reminder emails were sent a week after the preand post-survey administrations. Ten questions requiring Likert-scale responses were the same on both the pre- and posttest, and one question was unique to each instrument, totaling 12 Likert-scale questions in all (Table 2). In addition, the post-test also contained two questions to capture technology use by students (type of device, and type of internet access; Table 1). The responses to Likert-scale items were assigned quantitative ratings of Strongly Disagree (1), Disagree (2), Neutral (3), Agree (4), or Strongly Agree (5). A comment box was included at the end of both the pre- and post-test instruments with instructions for students to enter additional impressions about online learning not covered by the instrument.

Quantitative data are represented as Mean (SD). Comparison of Means between pre- and post-survey Likertresponses was performed using the Mann-Whitney U-test. The use of paired analysis was not possible because the student responses were anonymized. Instead, a standard statistical test for two independent groups was performed which would provide "conservative" results. ${ }^{24,25}$ 'Difference in Means' is abbreviated as 'DM' in the results section. Comparisons of class grades between the two cohorts (summer 2019 vs. summer 2020) were performed using Student's $t$-test. Quantitative data analyses were performed using MS Office Excel, and statistical analyses were performed using GraphPad Prism, version 9. For all statistical analyses, a $p<.05$ was considered statistically significant. Thematic analysis of qualitative data extracted from pre-/ post-survey instruments was performed independently by two investigators using the constant comparison method reported in literature. ${ }^{26,27}$ The authors have utilized this process previously in their work. ${ }^{28,29}$ Student comments were read several times for familiarization of data. Initial codes were generated manually by highlighting key text. Based on the context, the codes were grouped into categories. Some of these categories were collapsed or expanded as deemed necessary. Care was taken to ensure that the categories remained true to the opinions of the students. Finally, the categories were merged to generate overarching themes. Disagreements between investigators were resolved upon further discussion of the themes and achieving consensus. The data collection process was deemed to be exempt by the Institutional Review Board of the University.

\section{RESULTS}

Two different cohorts of students were enrolled in AS736 during summer 2019 (face-to-face instruction) and summer 2020 (online instruction). The class size was 25 in 2019 and 32 in 2020 . The distribution of sexes was approximately equal in both cohorts (Table 1). Most students in both cohorts had a bachelor's degree when they were admitted into the program, and it was their first quarter in the pharmacy program. The average ages were 36 and 33 for the 2019 and 2020 cohorts, respectively. While the 2019 cohort did not require computers for receiving instruction, most students in the 2020 cohort used personal laptops and a Wi-Fi internet connection to attend online lectures (Table 1).

Out of 32 students in the 2020 cohort, 31 completed the pre-test questionnaire, and 26 completed the post-test questionnaire (Table 2). As described in the methods section, three domains of student reception were assessed: transition to online learning, ease of technology, and instructor interaction. With respect to online learning, in the pre-test, student responses were mostly neutral for face-to-face instruction $(3.32$ (1.01)). However, their preference for face-to-face instruction decreased by the end of the quarter $(\mathrm{DM}=-1.59 ; p<.001$; Table 2). Although students anticipated that online 
learning would be as effective as face-to-face learning, their reception by the end of the quarter leaned more toward online learning being equally as effective ( $\mathrm{DM}=+0.63 ; p=.023)$. Students also felt AS736 should be continued to be offered online, and indicated that their online learning experience met their expectations for the course (4.38 (0.89)). With respect to technology, student level of comfort by the end of the quarter increased for attending online lectures $(\mathrm{DM}=+0.38 ; p$ $=.029)$, and taking assessments remotely ( $\mathrm{DM}=+0.57 ; p=.004)$ (Table 2$)$. However, there was no change in student perception for ease of technology used in online instruction $(p=.088)$. With respect to instructor interactions, student level of comfort increased for posing questions virtually to the instructor ( $\mathrm{DM}=+0.65 ; p=.019)$. However, there were no appreciable changes in reception regarding rapport development with the instructor, or believing that instructor's role is more important than the manner of course delivery (Table 2).

For the open-ended comment box on each questionnaire, 18 responses were received for the pre-survey, and 17 responses for the post-survey instruments. Qualitative thematic analysis of the pre-survey responses generated themes of reluctance to online learning, and general nervousness among the 2020 cohort (Table 3). Nonetheless, student reception altered positively toward online learning by the end of the quarter. Similar analysis of post-survey responses generated themes of overall acceptance to online learning, and consideration that online learning may be the preferred method of delivery for AS736 (Table 3). The grades of the midterm and final examinations for the 2019 cohort had a Mean(SD) of 95.7(5.45) and 84.6(5.58), respectively. The interquartile range (IQR) for the midterm grades was 7 (Median =98; Confidence Interval $(\mathrm{CI})=95.6 \%$ ), and the IQR for the final grades was 8 (Median =85, CI =95.6\%) for the 2019 cohort. Similarly, the grades of the midterm and final examinations for the 2020 cohort had a Mean(SD) of 94.3(3.89) and 78.2(11.7), respectively. The IQR for the midterm grades was 4.35 (Median =95.6; $\mathrm{CI}=97 \%$ ), and the IQR for the final grades was 11.3 (Median $=79.1, \mathrm{CI}=97 \%$ ) for the 2020 cohort. Grades from these two major class assessments when correspondingly cross compared between the two cohorts did not show significant differences (Midterm, $p=0.261 ;$ Final, $p$ $=0.075 ;$ Figure 1).

\section{DISCUSSION}

There has been a sudden surge in online teaching and learning in healthcare education during the last year because of the COVID-19 pandemic. While many articles have been published since then about effectively managing the crisis and continuing instruction aimed at educators, very little information is available concerning student readiness and reception to online learning amid this abrupt shift in instructional delivery. The present research is an effort to examine student readiness and monitor changes in reception toward completely online learning in a pharmacy course, along with comparison of student learning performance to that of a pre-pandemic, in-classroom cohort.

Overall student expectations from the online communications course (AS736) seem to have been met. Students admitted into the program already had some prior exposure to online instruction (Table 2). Nonetheless, their preference for online education had grown (ie, preference for face-to-face instruction declined) by the end of the course. It should be realized that prior association with online instruction and/ or comfort with technology does not necessarily translate to enhanced learning. Cook and colleagues demonstrated only a modest correlation between prior online learning experience and knowledge outcomes in medical residents over a nine-year period. ${ }^{30}$ Furthermore, there was no association between comfort with computers and enhanced learning in that study. Additional reports have indicated that, despite being technologically savvy, students may lack theoretical knowledge required for a particular profession. ${ }^{31}$ Moreover, student beliefs, expertise, and knowledge were all found to mutually influence one another in relation to student outcomes. ${ }^{32}$ The findings from the present study regarding preference for online learning resonate with those of a recent study, though asynchronous in its delivery, which captured student perceptions and performance in a blended pharmacy course. ${ }^{33}$ In that study, there was a decline of student preference for face-to-face instruction, and increased favorability for online learning.

Instructors undoubtedly play a crucial role in student learning. Alsharif and colleagues demonstrated how instructor attitude, enthusiasm, and teaching style impact student learning. ${ }^{34}$ Therefore, it was essential to investigate whether AS736 students could develop rapport with a remote instructor just as they would in a face-to-face classroom environment. It was reassuring to find that students did perceive developing rapport with the instructor. In fact, students strongly believed at the beginning of the quarter that the instructor's role is more important than the manner of delivery (face-to-face vs. online). Hence, their post-course impression did not change for these two items on the instrument (Table 2). Furthermore, the present study only considered the perception of rapport, not the actual measure of rapport. It may be difficult to isolate the effects of an intervention on rapport development as time will always be a confounding factor. The more the number of studentteacher interactions, the greater the rapport built irrespective of the mode of contact. In the context of this discussion, it is worth noting a recent analysis of refocusing instructor presence in higher education during remote learning. ${ }^{35}$ Three major areas of instructor roles were emphasized: 1) A cognitive role to take into consideration student preparedness and engagement in online learning experience. 2) A social role to sustain and likely improve student-student and student-teacher interaction. 3) And a facilitator role to directly integrate online tools/ resources into teaching practices. 
Thematic analysis of responses to the open-ended questions on the pre-/post-survey instruments echoed data from the corresponding Likert-scale item responses. While it is commonplace for students to be nervous before the online transition started, it was surprising to find reluctance to online learning in the pre-course evaluation data of students (Table 3). This may likely have arisen from one or a combination of the following probable factors. Firstly, students may have had unpleasant experiences of online learning in the past. Secondly, previous online learning experiences may not have been synchronous (the present study did not capture that information). Thirdly, students may have felt that communications, being a pragmatic skill seemingly requiring in-person interactions to be learned, was not suited for online instruction. This hypothesis stems from the observation that a fair number of students noted along similar lines, regarding class expectations, that 'Communications is most important for all pharmacists' (Table 3).

Tarhini and colleagues reported that the effectiveness of e-Learning is largely dependent on the end user's degree of acceptance. ${ }^{36}$ It was noticed in the present study that, by the end of the quarter, students had developed an attitude of acceptance toward online learning. Furthermore, if students have the necessary technical resources to support e-Learning, then this may positively impact their learning experience. For this likely reason, Al-Balas and colleagues have emphasized the necessity of collaboration with technology services to provide students with valuable support for e-Learning. ${ }^{37}$ In the online AS736 course, technical assistance was provided to students by the university's information technology department throughout the duration of the quarter. By the end of the quarter, students strongly supported the continuance of online education (Table 3). Several approaches to classroom learning during the pandemic have been proposed in the healthcare literature. The flipped classroom model, ${ }^{38}$ online interactive lectures,${ }^{39}$ blend of traditional and online learning, ${ }^{37}$ and asynchronous and synchronous remote delivery, ${ }^{18}$ have been suggested. Flexibility afforded to students was also an important element noted in continuing to provide online education. ${ }^{40}$

One of the objectives of the present study was to compare learning outcomes from the online cohort with those of the in-class face-to-face cohort. While the extent of variability in the midterm and final examination grades for the 2019 cohort was similar (IQR, 7 vs. 8), the variability in the midterm and final examination grades for the 2020 cohort was considerable (IQR, 4.35 vs. 11.3) (Figure 1). The large variability in the final grade for the online cohort is attributed to two students scoring below $50 \%$ on the examination. Although the difference in outcomes was not significant $(p=.075)$, there was an overall decrease in the final examination performance for the online cohort compared to the face-to-face (78.2(11.7) vs. 84.6(5.58)) (Figure 1). More student outcomes studies are warranted to conclusively determine if online learning hinders student performance. Reports within the pharmacy literature depict mixed results in student performance when online learning was compared to traditional classroom learning prior to the pandemic. For instance, Al-Dahir and colleagues noted students performed better in a face-to-face problem-based module than in an online module. ${ }^{14}$ In contrast, Porter and colleagues found no differences in student performance between online and face-to-face delivery in an elective course. ${ }^{12}$ In the present study, no significant differences were observed in student performance in AS736 across the two cohorts. This implies that online learning did not negatively impact student learning performance in this communications course. As the two cohorts were similar in age and possessed identical credentials prior to entering the program, we believe they represent similar student characteristics and learning potential. The findings from the present study concur with the observations reported by He and colleagues in a systematic review of healthcare education on remote learning. ${ }^{41}$ Their analysis did not conclude significant differences in effectiveness between online and traditional face-to-face learning. Studies in other healthcare professions reported that students can gain knowledge via e-Learning or face-to-face instruction; however, the level of student reception for e-Learning was mixed. ${ }^{42-44}$

Among the various challenges experienced during the online learning transition due to the pandemic, ensuring academic integrity during test-taking has been paramount. While the instructor proctored the 2019 cohort in a classroom setting on campus, Proctorio was utilized for the 2020 cohort. Proctorio is a completely secure, remote, and automated proctoring system. ${ }^{22}$ Data analytics and suspicious behaviors are captured during test-taking, and integrity reports are immediately available for review at the conclusion of the assessment. Every student in the 2020 cohort was required to turn on their camera before they took the online assessments. Computer-work anomalies such as navigating away from a test page, usage of keystrokes, mouse movements, and browser resizing, among others, could be monitored using Proctorio. In addition, environmental anomalies such as head movements, leaving the test room, and room audio, among others, could also be detected. Nonetheless, the severity of the threshold set for detecting these parameters is at the discretion of the examination administrator (course instructor). Having this remote proctoring system in place provided reasonable assurance of maintaining academic integrity during the test-taking process. Furthermore, results from recent studies have shown that online proctoring is an effective tool to mitigate academic dishonesty in courses administered online. ${ }^{45,46}$

There are several factors which are exclusive to this study in comparison to other investigations of online versus face-to-face learning. As proposed by Shalka, factors associated with uncommon events, such as those brought by the recent pandemic, can increase stress in student cohorts. ${ }^{47}$ Students may also have encountered a host of unprecedented psychological, social, and logistical problems in transitioning to online learning due to the emergency. Additionally, they 
may have had challenges maintaining concentration in learning because of prevalent safety concerns for themselves and their near ones. ${ }^{48}$ All these unique challenges set apart the students researched in the present study from those in other studies of online learning conducted outside the context of the pandemic.

This study has some limitations. Firstly, evaluation of student readiness to online learning and monitoring outcomes compared to those of a previous cohort was performed only in a single course (AS736) in the program. It was beyond the scope of investigators and program logistics to simultaneously conduct controlled experiments of student learning across other courses delivered in the curriculum. Nonetheless, since AS736 is a required course for the first-year cohort, the perceptions of students and their learning outcomes identified here could be extrapolated to other required courses delivered in the curriculum during the pandemic. This is because other required courses and their respective assessments were administered remotely using the same teleconferencing technology and proctoring system as was used for AS736. Secondly, technical difficulties, if any, related to Proctorio may also have influenced students' reception to the online method of instruction. Thirdly, the nervousness reported by some students in the pre-survey may have had other causes besides online learning. As mentioned earlier, this was their first quarter in the program, and it is commonplace for students to be nervous at the beginning of a new program irrespective of the delivery platform. Fourthly, the positive change in student reception toward online learning reported at the end of the quarter may have been influenced by experiences gathered beyond the communications course. Notably, the 2020 cohort was enrolled simultaneously in five other pharmacy courses all delivered online, which may have had a positive effect in changes in reception. Lastly, the class size was relatively small compared to the student cohorts in most other pharmacy schools and colleges, and represents a narrow student demographic.

\section{CONCLUSIONS}

The findings of the present study indicate that students were partly prepared for online learning at the course outset, with the remainder of their maturation to online learning occurring while the quarter progressed. Student learning performance for the online cohort did not differ significantly from that of the in-class face-to-face cohort the year before. Online learning existed prior to the COVID-19 pandemic in healthcare professions, and will likely remain after the crisis is over. Moving past the pandemic, educators and leadership at pharmacy schools and colleges may reassuringly continue to encourage and develop online instruction in their didactic curricula. The findings from this study may not only pertain to course delivery in the current pandemic, but might also be extrapolated to future e-Learning investigations. It remains to be determined how courses containing laboratory components and practice-based skills perform with online learning. Future studies may also be directed at gathering faculty perception and challenges faced in providing online instruction to healthcare students.

\section{ACKNOWLEDGEMENTS}

The authors would like to thank Dr. Gary Chan, Professor of Biostatistics, School of Public Health, University of Washington, Seattle, WA, for valuable discourses related to statistical analyses of data.

\section{REFERENCES:}

1. Wang CH, Shannon DM, Ross ME. Students' characteristics, self-regulated learning, technology self-efficacy, and course outcomes in online learning. Distance Educ. 2013;34(3):302-323.

2. Bourne JR. Net-Learning: Strategies for on-campus and off-campus network enabled learning. Online Learn. 1998;2(2):70-88.

3. Ruiz GJ, Mintzer MJ, Leipzig RM. The impact of E-learning in medical education. Acad Med. 2006;81(3):207212.

4. Dedeilia A, Sotiropoulos MG, Hanrahan JG, Janga D, et al. Medical and surgical education challenges, and innovations in the COVID-19 era: a systematic review. In Vivo. 2020;34(3 Suppl):1603-1611.

5. da Silva BM. Will virtual teaching continue after the COVID-19 pandemic? Acta Med Port. 2020;33(6):446.

6. Roskvist R, Eggleton K, Smith GF. Provision of e-learning programs to replace undergraduate medical students' clinical general practice attachments during COVID-19 stand-down. Educ Prim Care. 2020;31(4):247-254.

7. Kaur N, Dwivedi D, Arora J, Gandhi A. Study of the effectiveness of e-learning to conventional teaching in medical undergraduates amid COVID-19 pandemic. Natl J Physiol Pharm Pharmacol. 2020;10(7):1.

8. Sahi PK, Mishra D, Singh T. Medical education amid the COVID-19 pandemic. Indian Pediatr. 2020;57(7):652657.

9. Ahmady S, Shahbazi S, Heidari M. Transition to virtual learning during the coronavirus disease-2019 crisis in Iran: opportunity or challenge? Disaster Med Public Health Prep. 2020;14(3):1-2.11

10. Lee ICJ, Koh H, Lai SH, Hwang NC. Academic coaching of medical students during the COVID-19 pandemic. Med Educ. 2020;54(12):1184-1185. 
11. Longhurst GJ, Stone DM, Dulohery K, Scully D, et al. Strength, weakness, opportunity, threat (SWOT) analysis of the adaptations to anatomical education in the United Kingdom and Republic of Ireland in response to the Covid-19 pandemic. Anat Sci Educ. 2020;13(3):301-311.

12. Porter AL, Pitterle ME, Hayney MS. Comparison of online versus classroom delivery of immunization elective course. Am J Pharm Educ. 2014;78(5):Article 96.

13. Dirks-Naylor AJ, Baucom E. Impact of distance learning via synchronous videoconferencing on pharmacy student performance in a biological science course sequence. Adv Physiol Educ. 2019;43(4):534-536.

14. Al-Dahir S, Bryant K, Kennedy KB. Online virtual-patient cases versus traditional problem-based learning in advanced pharmacy practice experiences. Am J Pharm Educ. 2014;78(4):Article 76.

15. DeMella C, Donohoe K, Morgan L, Phipps L, et al. Implementation of an online ethics course into a pharmacy curriculum. Curr Pharm Teach Learn. 2017;9(5):835-840.

16. The role of the pharmacist in the health care system. Preparing the future pharmacist: curricular development report of a third WHO consultative group on the role of the pharmacist, Vancouver Canada, 27- 29 August 1997 (https://apps.who.int/iris/handle/10665/63817). Accessed May 7, 2021.

17. Wallman A, Vaudan C, Sporrong SK. Communications training in pharmacy education. Am J Pharm Educ. 2013;77(2): Article 36.

18. Lyons KM, Christopoulos A, Brock TP. Sustainable pharmacy education in the time of COVID-19. Am J Pharm Educ. 2020;84(6):Article 8088.

19. Wei H, Chou C. Online learning performance and satisfaction: do perceptions and readiness matter? Distance Educ. 2020;41(1):48-69.

20. Dray BJ, Lowenthal PR, Miszkiewicz MJ, Maria Araceli R, et al. Developing an instrument to assess student readiness for online learning: a validation study. Distance Educ. 2011;32(1):29-47.

21. Yu T, Richardson JC. An exploratory factor analysis and reliability analysis of the student online learning readiness (SOLR) instrument. Online Learn. 2015;19(5):120-141.

22. A comprehensive learning integrity platform, www.proctorio.com, Accessed May 7, 2021.

23. O'Doherty D, Dromey M, Lougheed J, Hannigan A, et al. Barriers and solutions to online learning in medical education- an integrative review. BMC Med Educ. 2018;18(1):130.

24. Ryan-Ibarra S, DeLisio A, Bang H, Adekokun O, et al. The US supplemental nutrition assistance program: education improves nutrition-related behaviors. J Nutr Sci. 2020;30(9):e44

25. Bain L, Engelhardt M. Introduction to Probability and Mathematical Statistics. Boston: Cengage Learning; 2000.

26. Braun V, Clarke V. Using thematic analysis in psychology. Qual Res Pscychol. 2006;3(2):77-101.

27. Castleberry A, Nolen A. Thematic analysis of qualitative research data: is it as easy as it sounds? Curr Pharm Teach Learn. 2018;10(6):807-815.

28. Islam MA, Talukder RM, Taheri R, Blanchard N. Integration of basic and clinical science courses in US PharmD programs. Am J Pharm Educ. 2016;80(10):Article 166.

29. Islam MA, Taheri R, McBane S, Talukder RM. Faculty assessment of scholarship of teaching and learning among united states pharmacy programs. Curr Pharm Teach Learn. 2020;12(10):1163-1170.

30. Cook DA, Thompson WG. Comfort and experience with online learning: trends over nine years and associations with knowledge. BMC Med Educ. 2014;14:Article 128.

31. Ali W. Online and remote learning in higher education institutes: a necessity in light of COVID-19 pandemic. High Educ Stud. 2010;10(3):16-25.

32. Bower M. Technology-mediated learning theory. Brit J Educ Tech. 2019;50(3):1035-1048.

33. Hughes P, Waldrop B, Chang J. Student perceptions of and performance in a blended foundational drug information course. Curr Pharm Teach Learn. 2016;8(3):359-363.

34. Alsharif NZ, Qi Y. A three year study of the impact of instructor attitude, enthusiasm, and teaching style on student learning in a medicinal chemistry course. Am J Pharm Educ. 2014;78(7):Article 132.

35. Rapanta C, Botturi L, Goodyear P, Guardia L, et al. Online university teaching during and after the COVID-19 crisis: refocusing teacher presence and learning activity. Postdigit Sci Educ. 2020;2:923-945.

36. Tarhini A, Hone K, Liu X, Tarhini T. Examining the moderating effect of individual-level cultural values on users' acceptance of E-learning in developing countries: a structural equation modeling of an extended technology acceptance model. Inter Learn Environ. 2016;25(3):306-328.

37. Al-Balas M, Al-Balas HI, Jaber HM, et al. Distance learning in clinical medical education amid COVID-19 pandemic in Jordan: current situation, challenges, and perspectives. BMC Med Educ. 2020;20:Article 341.

38. Verma A, Verma S, Garg P, Godara R. Online teaching during COVID-19: perception of medical undergraduate students. Indian J Surg. 2020;82(3):299-300. 
39. Manalo TA, Higgins MI, Pettitt-Schieber B, et al. A strategy for undergraduate medical education in urology during the COVID-19 pandemic. J Surg Educ. 2020;S1931-7204(20)30361-5.

40. Schlesselman LS. Perspective from a teaching and learning center during emergency remote teaching. Am J Pharm Educ. 2020;84(8):Article 8142.

41. He L, Yang N, Xu L, Ping F, et al. Synchronous distance education vs traditional education for health science students: A systematic review and meta-analysis. Med Educ. 2021;Article 14364 (In press).

42. Turkyilmaz I, Hariri NH, Jahangiri L. Student's perception of the impact of E-learning on dental education. $J$ Contemp Dent Pract. 2019;20(5):616-621.

43. Cohen NL, Carbone ET, Beffa-Negrini PA. The design, implementation, and evaluation of online credit nutrition courses: a systematic review. J Nutr Educ Behav. 2011;43(2):76-86.

44. Wang C, Xie A, Wang W, Wu H. Association between medical students prior experiences and perceptions of formal online education developed in response to COVID-19: a cross sectional study in China. Brit Med J. 2020;10(10):Article 041886.

45. Dendir S, Maxwell RS. Cheating in online courses: evidence from online proctoring. Comput Hum Behav. 2021;2:Article 100033.

46. Bilen E, Matros A. Online cheating amid COVID-19. J Econ Behav Organ. 2021;182:196-211.

47. Shalka TR. Saplings in the hurricane: a grounded theory of college trauma and identity development. Rev Higher Educ. 2019;42(2):739-764.

48. Besser A, Flett G, Zeigler-Hill V. Adaptability to a sudden transition to online learning during the COVID-19 pandemic: understanding the challenges to students. Scholarsh Teach Learn Psychol. Advance online publication, http://dx.doi.org/10.1037/st10000198. 
Table 1. Demography \& Technology Information of Students Enrolled in Face-to-face (2019) and Online (2020) Learning in AS736 Course
Face-to-face
Online
(Year 2019)
(Year 2020)
$\S_{N}=25$
$\S_{N}=32$

Demographic Info

Sex

$\begin{array}{lll}\text { Male } & 12 & 16 \\ \text { Female } & 13 & 16 \\ \text { ge Age } & 36 & 33\end{array}$

Highest degree earned

No degree

Associate

Bachelor's

$\begin{array}{cc}5 & 2 \\ 1 & 20 \\ 19 & 3 \\ - & \end{array}$

Type of Device a

Desktop computer 3

Personal laptop $\quad 20$

Tablet 7

Smart phone 6

Type of internet

Direct cable 3

Wi-fi

${ }^{\S} \mathrm{N}=$ Respective class sizes for the two cohorts

${ }^{\text {a }}$ The total number of devices being more than 31 is attributed to 5 students using more than one device to log-in for online learning. 31 out of 32 took the pre-survey 


\begin{tabular}{|c|c|c|c|}
\hline Question & $\begin{array}{c}\text { Pre-Survey } \\
\text { Mean (SD) } \\
\mathbf{N}=\mathbf{3 1} \\
\end{array}$ & $\begin{array}{c}\text { Post-Survey } \\
\text { Mean (SD) } \\
\mathbf{N}=\mathbf{2 6} \\
\end{array}$ & $p$ value \\
\hline \multicolumn{4}{|l|}{ Online learning } \\
\hline 1. I have prior experience taking classes virtually & $3.90(1.16)$ & - & $\mathrm{n} / \mathrm{a}$ \\
\hline 2. I prefer attending lectures face-to-face than over the internet & $3.32(1.01)$ & $1.73(0.83)$ & $<.001$ \\
\hline 3. Online learning will be/ was as effective as in-class learning & $3.45(1.09)$ & $4.08(1.13)$ & .023 \\
\hline 4. Online instruction will allow/ allowed me the flexibility to attend lectures from any place & $4.19(0.94)$ & $4.50(0.86)$ & .175 \\
\hline 5. I feel AS736 course should be delivered face-to-face than online & $3.00(1.18)$ & $1.76(0.91)$ & $<.001$ \\
\hline 6. Online learning experience met my expectations for this course & - & $4.38(0.89)$ & $\mathrm{n} / \mathrm{a}$ \\
\hline \multicolumn{4}{|l|}{ Ease of technology } \\
\hline 7. I will be/ was comfortable attending lectures virtually & $4.23(0.84)$ & $4.61(0.75)$ & .029 \\
\hline 8. I will be/ was comfortable with technology used in online instruction & $4.13(0.97)$ & $4.48(0.92)$ & .088 \\
\hline 9. I will be/ was comfortable taking quizzes and exams remotely & $4.07(0.87)$ & $4.64(0.64)$ & .004 \\
\hline \multicolumn{4}{|l|}{ Instructor interactions } \\
\hline $\begin{array}{l}\text { 10. I will develop/ developed professional rapport (student-teacher relationship) with my } \\
\text { instructor in a virtual set-up }\end{array}$ & $3.64(1.35)$ & $4.23(0.86)$ & .147 \\
\hline 11. I will be/ was comfortable asking questions to my instructor in a virtual set-up & $3.93(1.09)$ & $4.58(0.65)$ & .019 \\
\hline $\begin{array}{l}\text { 12. Instructor's role is more important than the manner (online vs. face-to-face) a course is } \\
\text { delivered }\end{array}$ & $4.23(0.80)$ & $4.27(0.87)$ & .761 \\
\hline
\end{tabular}

\footnotetext{
$\S 1=$ Strongly Disagree, 2=Disagree, 3=Neutral, 4=Agree, 5=Strongly Agree
} 


\section{Pre-Survey}

Reluctance to online learning

Feeling of nervousness

Class expectation

\section{Post-Survey}

Acceptance to online learning

Online learning is the future

Class reception
Will not stay motivated

I'll have to communicate via chatting during class

You feel it and live it while in-person

Quality of lecture will not be same as in-class

Don't enjoy online

I'll not be able to cope up with online learning

It will be a challenge for me

2

I am little nervous, it's a new setting

We will be muted most of the times

Will not be as fulfilling as in-class

Looking forward to role-playing

This is training for life, doing my dream

Communication is most important for all pharmacists

2

Felt I was always in-class

I am now adjusted and learned to love online setting

Easy and accessible

Hiccups in beginning; but once we got used to it, it became very helpful

Physical presence in classroom is not as important

I don't mind keeping it this way

Strongly support online studies

New direction to learning with technology

\section{Met all my expectations}

Interactions with classmates has been great

Time I would have spent driving, I spent studying

Professor has been available one-on-one for office hours just like in-

\footnotetext{
$\S 18$ pre-survey comments and 17 post-survey comments

${ }^{\text {a }}$ Retained in original format, including typos, if any
} 
Figure 1. Comparison of Examination Grades Using Box-and-Whisker Plot for the Cohorts in Face-to-face (2019; N=25) and Online (2020; N=32) Learning in AS736 Course

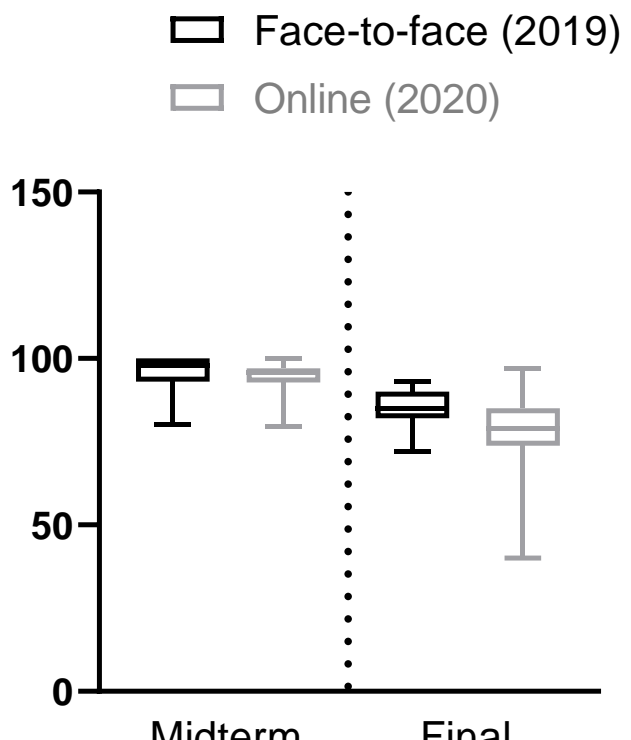

Midterm Final 